\title{
Metabolism of Natural Highly Unsaturated Fatty Acid, Tetracosahexaenoic Acid (24:6n-3), in C57BL/KsJ-db/db Mice
}

\author{
Naohiro Gotoh ${ }^{1 *}$, Koji Nagao², Hiroki Ishida', Kazusa Nakamitsu², Kazuaki Yoshinaga ${ }^{3}$, \\ Toshiharu Nagai ${ }^{3}$, Fumiaki Beppu ${ }^{1}$, Aya Yoshinaga-Kiriake ${ }^{1}$, Hiroyuki Watanabe ${ }^{4}$, and \\ Teruyoshi Yanagita ${ }^{5}$ \\ ${ }^{1}$ Department of Food Science and Technology, Tokyo University of Marine Science and Technology, 4-5-7 Konan, Minato-ku, Tokyo 108-8477, \\ JAPAN \\ ${ }^{2}$ Department of Applied Biochemistry and Food Science, Saga University, 1 Honjo-machi, Saga-shi, Saga 840-8502, JAPAN \\ ${ }^{3}$ Tsukishima Foods Industry Co. Ltd. (3-17-9, Higashi Kasai, Edogawa-ku, Tokyo 134-8520, JAPAN \\ ${ }^{4}$ Department of Health Science, University of Kochi, 2751-1 Ike, Kochi-shi, Kochi 781-0111, JAPAN \\ ${ }^{5}$ Department of Health and Nutrition Science, Nishikyushu University, 4490-9 Ozaki, Kanzaki-machi, Kanzaki-shi, Saga 842-8585, JAPAN
}

\begin{abstract}
Tetracosahexaenoic acid (THA; 24:6n-3) is a natural, n-3 highly unsaturated fatty acid (n-3HUFA) that exists in fish, including Baltic herring (Clupea harengus) and the flathead flounder (Hippoglossoides dubius). In this study, natural n-3HUFAs, i.d. eicosapentaenoic acid (EPA, 20:5n-3), docosahexaenoic acid (DHA, 22:6n-3), and THA were administrated to C57BL/KsJ-db/db mice for 4 weeks and the liver and serum lipid profiles, hepatic enzyme activity, expression of mRNA related to lipid metabolism, and adiponectin serum levels were then analyzed. The results showed that THA had the highest activity in suppressing hepatic triglyceride (TG) accumulation and increase in liver weight among the test groups. Furthermore, THA increased adiponectin levels in serum. These results indicate that THA is an excellent natural n-3HUFA that can suppress the development of metabolic syndromes and circulatory system diseases. The order of the n-3HUFA activity was THA $>$ DHA $>$ EPA in almost all the factors examined here. In a previous study of ours, the order was DHA $>$ DPA $>$ EPA, so the final order was summarized as THA $>$ DHA > DPA > EPA. This order clearly translates to the rule that "the number of double bonds and carbon atoms in the n-3HUFA structure relates to their clinical functions".
\end{abstract}

Key words: tetracosahexaenoic acid, n-3 polyunsaturated fatty acid, function, docosahexaenoic acid, eicosapentaenoic acid, $\mathrm{C} 57 \mathrm{BL} / \mathrm{KsJ}-\mathrm{db} / \mathrm{db}$ mice

\section{INTRODUCTION}

Metabolic syndrome is associated with an increased risk of developing diabetes and cardiovascular disease. It is also associated with the accumulation of triglyceride (TG) in the liver and increased levels of cholesterol(Ch) and TG in the blood. Both genetic and dietary factors are known to play a role in the onset of the syndrome ${ }^{1-3)}$. For example, the Japanese have a much lower rate of cardiovascular disease compared to the Europeans and Americans ${ }^{4)}$. One of the reasons for this is thought to be the fact that fish has played a central role in the Japanese diet for a long time ${ }^{5)}$. Fish oil possesses attributes that can suppress the development of cardiovascular diseases and could play a role in the improvement of the pathogenic mechanism of metabolic syndrome $^{6,7)}$. The European Society of Cardiology, the European Atherosclerosis Society, and the American Heart Association all promote diets low in calories and certain fats ${ }^{8,9)}$. High-quality fats are thought to promote good health, especially those found in fish, such as n-3 type fatty $\operatorname{acids}^{8,9)}$.

Fish oil contains many types of n-3 highly unsaturated fatty acids (n-3HUFA), including eicosapentaenoic acid (EPA, 20:5n-3) and docosahexaenoic acid (DHA, 22:6n-3). These fatty acids have the ability to decrease the amount of TG in the liver ${ }^{10)}$, the levels of Ch and TG in the blood ${ }^{11)}$, accumulation of visceral fat ${ }^{12)}$, and to increase the levels of

\footnotetext{
*Correspondence to: Naohiro Gotoh, Department of Food Science and Technology, Tokyo University of Marine Science and Technology, 4-5-7 Konan, Minato-ku, Tokyo 108-8477, JAPAN

E-mail: ngotoh@kaiyodai.ac.jp

Accepted August 28, 2018 (received for review August 20, 2018)

Journal of Oleo Science ISSN 1345-8957 print / ISSN 1347-3352 online

http://www.jstage.jst.go.jp/browse/jos/ http://mc.manusriptcentral.com/jjocs
} 
adiponectin in the blood ${ }^{13)}$, among others. EPA has been used as a drug to decrease TG levels in the blood ${ }^{14)}$. DHA also improves lipid metabolism, so much so that the Ministry of Health, Labor, and Welfare in Japan approved certain DHA-enriched foods as Food for Specified Health Use ${ }^{15)}$. Docosapentaenoic acid (DPA, 22:5n-3) is also a well-known $\mathrm{n}-3$ HUFA that is found in seal oil ${ }^{16)}$ and that consists of the same numbers of double bonds in EPA and carbon atoms in DHA. Specifically, the structure is an intermediate of EPA and DHA. The abilities of EPA, DPA, and DHA to improve the lipid profiles in the blood, lipid metabolism, adiponectin, etc., were investigated using C57BL/KsJ-db/ $d b$ mouse $^{17)}$. Interestingly, our results for all the observed factors using DPA were between EPA and DHA. These results indicate that the clinical function derived from n-3HUFA relates to both the number of double bonds and carbon atoms. Particularly, the increased ability of adiponectin was the lowest in the EPA treatment group and the highest in DHA treatment group among the three n-3HUFAs; therefore, DHA was thought to be the strongest n-3HUFA for the suppression of metabolic syndrome and cardiovascular disease progress. DHA is an n-3HUFA synthesized from EPA by elongation and desaturation reactions in our body. EPA is elongated to form DPA at first; however, humans do not possess $\Delta 4$ desaturase that can form DHA from DPA directly ${ }^{18)}$. Therefore, DPA is elongated again to form tetracosapentaenoic acid (24:5n-3) and desaturated by $\Delta 6$ desaturase. As a result, tetracosahexaenoic acid (THA, 24:6n-3) forms. THA is beta-oxidized to form DHA. THA is also one of the n-3HUFAs found in fishes such as Baltic herring (Clupea harengus) and the flathead flounder(Hippoglossoides dubius), among others ${ }^{19-21)}$. THA consists of 24 carbon atoms and 6 double bonds. Specifically, the number of carbon atoms in THA is two more compared to that in DHA. As indicated above, the health function benefits of n-3HUFA is related to the number of double bonds and carbon atoms in n-3HUFA. According to this rule, THA might act as the strongest n-3HUFA for the suppression of visceral fat accumulation, increasing adiponectin levels, improving the lipid profile in blood and liver, suppressing the development of metabolic syndrome, and suppressing the progress of atherosclerotic diseases. In fact, we already compared the lipid metabolism ability among these four kinds of n-3HUFA, using HepG2 cells ${ }^{22)}$. The results showed that THA exerted the strongest suppression on the synthesis of triglyceride and cholesteryl ester (ChE), and the order of the suppression strength was $\mathrm{THA}>\mathrm{DHA}>\mathrm{DPA}>\mathrm{EPA}$, as we predicted previously.

Therefore, in this study, we examined the health-related functions of THA in $\mathrm{C} 57 \mathrm{BL} / \mathrm{KsJ}-d b / d b$ mice to confirm the results obtained from the HepG2 cells, and the number of double bonds and carbon atoms rule in n-3HUFA. This study could provide us with a basic understanding of the development of new medicines for treating metabolic syn- drome.

\section{MATERIALS AND METHODS}

\subsection{Chemicals and materials}

All the AAA-type TGs such as tripalmitate (tri16:0), trioleate (tri18:1n-9), trilinoleate (tri18:2n-6), trilinolenate (tri18:3n-3), triEPA, triDHA, and triTHA were obtained from Tsukishima Foods Industry Co., Ltd(Tokyo, Japan). The purity of the fatty acids consisting of AAA-type TG was greater than 98\%. 5,5' -Dithiobis (2-nitro-benzoic acid) was purchased from Tokyo Chemical Industry Co., Ltd. (Tokyo, Japan). Beta-corn starch, cellulose, nicotinamide adenine dinucleotide, reduced nicotinamide adenine dinucleotide, and reduced nicotinamide adenine dinucleotide phosphate were obtained from Oriental Yeast Co., Ltd. (Tokyo, Japan). Triton X-100, 6-phosphogluconatedehydrogenase, dithiothreitol, casein, $d l$-methionine, and choline bitartrate were purchased from Wako Pure Chemical Industries, Ltd. (Osaka, Japan). Mineral mixture (AIN-76) and vitamin mixture (AIN-76) were purchased from Nosan Corporation(Tokyo, Japan). Sucrose was obtained from Mitsui Sugar Co., Ltd. (Tokyo, Japan). Silica gel (silicic acid 100 mesh) was purchased from Mallinckrodt Baker, Inc. (Phillipsburg, NJ). Palmitoyl CoA was obtained from Funakoshi Co., Ltd. (Tokyo, Japan). Glucose 6-phosphate was purchased from Calzyme Laboratories, Inc. (San Luis Obispo, CA). Acetyl CoA, $l$-malic acid, malonyl CoA, $l$ carnitine, flavin adenine dinucleotide (FAD), phosphatidylcholines, and phosphatidic acid were bought from SigmaAldrich, Japan K.K. (Tokyo, Japan). Other reagents were obtained from Wako Pure Chemical Industries, Ltd. (Osaka, Japan). Structures of EPA, DPA, DHA, and THA are compared in Fig. 1.

\subsection{Animal test}

All experiments were performed in accordance with the Saga University guidelines for animal use and care provided by the ethics committee (No. 22-042-1). Five-week-old male C57BL/6J mice and C57BL/KsJ- $d b / d b$ mice were bought from Nippon Clea Co. (Tokyo, Japan). The mice were housed individually in plastic cages lined with sawdust in a temperature $\left(23 \pm 2^{\circ} \mathrm{C}\right)$ and light $(12$-h cycle $)$ controlled environment. The mice were initially fed a com-
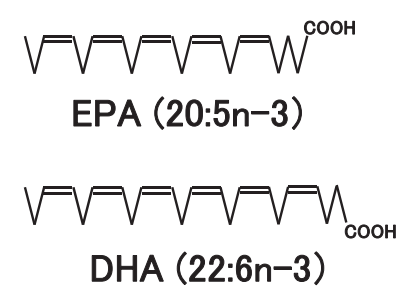
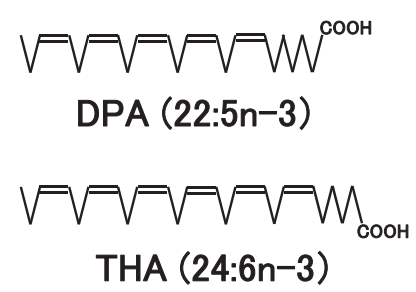

Fig. 1 The structure of n-3HUFAs. 
mercial diet CE-2 (Nippon Clea Co.) for 1 week and then divided into four groups: Control group (control diet; $\mathrm{n}=$ 5), EPA-TG Group ( $1 \%[\mathrm{w} / \mathrm{w}]$ of trilinoleate in the control diet was replaced with triEPA; $n=5)$, DHA-TG group (1\% of trilinoleate in control diet was replaced with triDHA; $n=$ 5 ), and THA-TG group (1\% of trilinoleate in control diet was replaced with triTHA; $n=5$ ). TG comprised $9 \%$ of the control diet and consisted of tripalmitate $(3 \%)$, trioleate $(3 \%)$, trilenoleate $(2.9 \%)$, and trilinolenate $(0.1 \%)$. All the diets were prepared based on an AIN-76 composition. The detailed diet composition is shown in Table 1. Each group of C57BL/KsJ- $d b / d b$ mice was given their diet for 4 weeks by pair-feeding. Furthermore, as the positive control group, a group of C57BL/6J mice was also fed a control diet for 4 weeks (Normal Control). All the mice were allowed free access to water. The weight and consumption amount of the feed for each mouse were measured every day. At the end of the feeding period, the mice were killed by withdrawing blood from the heart under isoflurane anesthesia after a 9-h starvation period. The liver, muscles, heart, kidney, testis, brain, epididymal fat, adrenal grand, and spleen were harvested. All the organs and tissues were preserved in liquid nitrogen. The withdrawn blood samples were centrifuged at $1750 \times g$ for $15 \mathrm{~min}$ at $4^{\circ} \mathrm{C}$ to collect the sera.

\subsection{Serum analysis}

Serum TG and cholesterol levels were analyzed using commercial enzyme assay kits (Wako Pure Chemical Indus- tries, Ltd.). Insulin and adiponectin levels were measured using an Insulin ELISA kit (Shibayagi Co. Ltd., Gunma, Japan) and Mouse/Rat Adiponectin ELISA kit(Otsuka Pharmaceutical Co., Ltd., Tokyo, Japan), respectively. Alanine aminotransferase (ALT) activity was analyzed using a Transaminase CII-test Wako kit (Wako Pure Chemical Industries, Ltd.).

\subsection{Liver lipid analysis}

Hepatic lipid was extracted from the liver by the method described by Folch et $a l^{23)}$. Hepatic concentrations of TG and phospholipid were measured according to the methods described by Fletcher et $a l .{ }^{24)}$ and Rouser et $a l .{ }^{25)}$, respectively. Hepatic cholesterol concentration was analyzed using the Cholesterol E-Test Wako (Wako Pure Chemical Industries, Ltd.).

\subsection{Hepatic enzyme activity assay}

Liver mitochondrial and cytosol fractions were prepared by homogenization and centrifugation. The protein concentration of each fraction was analyzed by the method of Lowry ${ }^{26)}$. The enzyme activity of fatty acid synthase $(\mathrm{FAS})^{27)}$ and glucose 6 -phosphate dehydrogenase $(\mathrm{G} 6 \mathrm{PDH})^{28}$ in each cellular fraction was measured by the method of Kelly. Malic enzyme (ME), carnitine palmitoyl transferase (CPT), peroxisomal $\beta$-oxidation, and phosphatidate phosphohydrolase (PAP) in each cellular fraction were assayed by the method of Ochoa et $a l .{ }^{29)}$, Markwell et $a l .{ }^{30)}$, Lazarow et $a l_{.}{ }^{31)}$, and Walton et $a{ }^{32)}$, respectively.

Table 1 Composition of the experimental $\operatorname{diet}(\mathrm{g} / 100 \mathrm{~g})$.

\begin{tabular}{|c|c|c|c|c|c|}
\hline Ingredient & $\begin{array}{l}\text { Normal Control } \\
\text { Group }\end{array}$ & Control Group & EPA-TG Group & DHA-TG Group & THA-TG Group \\
\hline & $(\mathrm{C} 57 \mathrm{BL} / 6 \mathrm{~J})$ & \multicolumn{4}{|c|}{$(\mathrm{C} 57 \mathrm{BL} / \mathrm{KsJ}-d b / d b)$} \\
\hline Casein & 20.00 & 20.00 & 20.00 & 20.00 & 20.00 \\
\hline Corn starch & 15.00 & 15.00 & 15.00 & 15.00 & 15.00 \\
\hline Cellulose & 5.00 & 5.00 & 5.00 & 5.00 & 5.00 \\
\hline Mineral mixture (AIN-76) & 3.50 & 3.50 & 3.50 & 3.50 & 3.50 \\
\hline Vitamin mixture (AIN-76) & 1.00 & 1.00 & 1.00 & 1.00 & 1.00 \\
\hline DL-Methionine & 0.30 & 0.30 & 0.30 & 0.30 & 0.30 \\
\hline Choline bitartrate & 0.20 & 0.20 & 0.20 & 0.20 & 0.20 \\
\hline Tripalmitate (triPA) & 3.00 & 3.00 & 3.00 & 3.00 & 3.00 \\
\hline Trioleate (triOA) & 3.00 & 3.00 & 3.00 & 3.00 & 3.00 \\
\hline Trilinoleate (triLA) & 2.90 & 2.90 & 1.90 & 1.90 & 1.90 \\
\hline Trilinolenate (triLnA) & 0.10 & 0.10 & 0.10 & 0.10 & 0.10 \\
\hline TriEPA & - & - & 1.00 & - & - \\
\hline TriDHA & - & - & - & 1.00 & - \\
\hline TriTHA & - & - & - & - & 1.00 \\
\hline Sucrose & 46.00 & 46.00 & 46.00 & 46.00 & 46.00 \\
\hline
\end{tabular}




\subsection{Hepatic mRNA level assay}

Total RNA was extracted from $100 \mathrm{mg}$ of liver, using the RNeasy Lipid Tissue Mini Kit (Qiagen, Tokyo, Japan). A TaqMan® Universal PCR Master Mix (Applied Biosystems, Tokyo, Japan), an Assays-on-Demand ${ }^{\mathrm{TM}}$, Gene Expression Product (Mm01304289_m1 for acetyl-CoA carboxylase 1 (ACC1), Mm01204659_m1 for acetyl-CoA carboxylase 2 (ACC2), Mm00662319_m1 for fatty acid synthase(FAS), Mm00517221_m1 for delta 6 desaturase(D6D), Mm00550338_m1 for sterol regulatory element binding protein -1 (SREBP1), Mm00441242_m1 for monocyte chemoattractant protein 1 (MCP1), Mm03928991_g1 for 18S rRNA (Applied Biosystems, Tokyo, Japan), and the TaqMan ${ }^{\circledR}$ MGB Gene Expression Kits (Applied Biosystems) for stearoyl-coenzyme A desaturase-1: SCD1 (forward primer, 5'-AGCCTGTTCGTCAGCACCTT-3'; reverse primer, 5'-CACCCAGGGAAACCAGGAT-3'; and TaqMan® MGB probe, 5'-FAM-CACTCTGGTGCTCAACMGB-3') were used for quantitative real-time RT-PCR analysis of ACC1, ACC2, FAS, D6D, SREBP1, MCP1, SCD1, and $18 \mathrm{~S}$ rRNA expression in the liver. The amplification was performed on a real-time PCR system (ABI Prism 7000 Sequence Detection System; Applied Biosystems). The results were expressed as a relative value after normalization to the 18S RNA expression.

\subsection{Analysis of fatty acid composition in organs and tissues}

Lipids contained in the organs and tissues were also extracted by the method described by Folch et $a l^{23)}$. The extracted lipids were dried and weighed. Methyl esterification of the extracted lipids was performed using a boron trifluoride methanol solution. The methyl-esterified fatty acid was subjected to a gas chromatography-flame ionization detector (GC-FID) system (GC-14B, Shimadzu, Tokyo, Japan) equipped with a capillary column (Omegawax320, $30 \mathrm{~m} \times 0.25$ mm ID, SIGMA-ALDRICH Japan K.K., Tokyo, Japan) and a Chromatopac integrator (C-R6A; Shimadzu) to analyze the fatty acid composition and relative ratio. The temperature of the injection port and detector was $250^{\circ} \mathrm{C}$ and $260^{\circ} \mathrm{C}$, respectively. The initial column temperature of $175^{\circ} \mathrm{C}$ was increased to $225^{\circ} \mathrm{C}$ at a rate of $1^{\circ} \mathrm{C} / \mathrm{min}$. Helium was used as the carrier gas at a flow rate of $32 \mathrm{~cm} / \mathrm{s}$. The fatty acid species were identified using the retention time of a fatty acid methyl ester standard solution (Supelco 37 Component FAME Mix, SIGMA-ALDRICH Japan K.K.). The relative contents of the respective fatty acids were calculated using a GC-FID chromatogram.

\subsection{Statistical analyses}

All values are expressed as means $\pm \mathrm{SE}$. Data were ana-

Table 2 Effect of experimental diet on growth parameters in C57BL/6J and C57BL/KsJ-db/db mice.

\begin{tabular}{|c|c|c|c|c|c|}
\hline & $\begin{array}{c}\text { Normal Control } \\
\text { Group }\end{array}$ & Control Group & EPA-TG Group & DHA-TG Group & THA-TG Group \\
\hline & $(\mathrm{C} 57 \mathrm{BL} / 6 \mathrm{~J})$ & \multicolumn{4}{|c|}{$(\mathrm{C} 57 \mathrm{BL} / \mathrm{KsJ}-d b / d b)$} \\
\hline Initial body weight (g) & $20.1 \pm 0.2$ & $28.8 \pm 0.8 *$ & $28.8 \pm 0.5$ & $28.8 \pm 0.6$ & $28.8 \pm 0.4$ \\
\hline Final body weight (g) & $22.1 \pm 0.2$ & $37.0 \pm 1.7 *$ & $37.9 \pm 0.6$ & $36.3 \pm 1.0$ & $35.6 \pm 1.5$ \\
\hline Total weight gain (g) & $2.00 \pm 0.16$ & $8.20 \pm 1.46 *$ & $9.10 \pm 0.35$ & $7.50 \pm 0.61$ & $6.84 \pm 1.06$ \\
\hline Total food intake $(\mathrm{g})$ & $78.2 \pm 1.1$ & $136 \pm 5 *$ & $136 \pm 3$ & $136 \pm 4$ & $135 \pm 3$ \\
\hline Food efficiency (mg gain/g intake) & $25.6 \pm 2.0$ & $61.3 \pm 12.5 *$ & $66.9 \pm 3.0$ & $55.1 \pm 4.0$ & $49.9 \pm 6.7$ \\
\hline Liver weight ( $\mathrm{g} / 100 \mathrm{~g}$ body weight) & $4.07 \pm 0.07$ & $5.46 \pm 0.21 *^{\mathrm{a}}$ & $4.50 \pm 0.13^{\mathrm{b}}$ & $4.62 \pm 0.07^{\mathrm{b}}$ & $4.46 \pm 0.11^{\mathrm{b}}$ \\
\hline Testis (g) & $0.196 \pm 0.012$ & $0.148 \pm 0.010 *$ & $0.152 \pm 0.005$ & $0.135 \pm 0.008$ & $0.124 \pm 0.010$ \\
\hline Kidney (g) & $0.277 \pm 0.006$ & $0.378 \pm 0.005 *$ & $0.382 \pm 0.013$ & $0.397 \pm 0.011$ & $0.393 \pm 0.013$ \\
\hline Adrenal grand (mg) & $5.56 \pm 0.68$ & $6.52 \pm 0.54$ & $5.52 \pm 0.40$ & $5.02 \pm 0.19$ & $5.54 \pm 0.71$ \\
\hline Spleen (mg) & $56.2 \pm 0.6$ & $34.0 \pm 2.7 *$ & $45.2 \pm 1.7$ & $36.8 \pm 2.2$ & $32.8 \pm 0.2$ \\
\hline Heart $(\mathrm{g})$ & $0.114 \pm 0.002$ & $0.121 \pm 0.002 *$ & $0.125 \pm 0.002$ & $0.114 \pm 0.002$ & $0.110 \pm 0.003$ \\
\hline Brain $(g)$ & $0.452 \pm 0.004$ & $0.393 \pm 0.004 *$ & $0.394 \pm 0.003$ & $0.380 \pm 0.011$ & $0.382 \pm 0.005$ \\
\hline \multicolumn{6}{|c|}{ Accumulated fat (white adipose tissue) weight ( $\mathrm{g} / 100 \mathrm{~g}$ body weight) } \\
\hline Total & $2.27 \pm 0.19$ & $12.0 \pm 0.3 *$ & $12.0 \pm 0.3$ & $11.2 \pm 0.2$ & $10.9 \pm 0.6$ \\
\hline Epididymal & $1.17 \pm 0.08$ & $5.23 \pm 0.06 *$ & $5.10 \pm 0.19$ & $4.80 \pm 0.10$ & $5.00 \pm 0.11$ \\
\hline Perirenal & $0.489 \pm 0.034$ & $2.98 \pm 0.13 *$ & $3.08 \pm 0.12$ & $2.95 \pm 0.08$ & $2.65 \pm 0.12$ \\
\hline Omental & $0.607 \pm 0.093$ & $3.83 \pm 0.20 *$ & $3.87 \pm 0.08$ & $3.43 \pm 0.11$ & $3.82 \pm 0.10$ \\
\hline
\end{tabular}

Each value represents mean \pm SE $(n=5)$.

Different letters indicate significant difference at $p<0.05$ among C57BL/KsJ- $d b / d b$ groups.

$* p<0.05$ (Normal Control vs Control group) 
lyzed by one-way ANOVA, and all differences were inspected by Tukey-Kramer post-hoc test (Kaleida Graph, Synergy Software, Reading, PA). Differences between the Normal Control and the Control group in the animal test were evaluated by Student's $t$-test. The difference was considered significant when $P$ was less than 0.05 .

\section{RESULTS}

\subsection{Weight change}

Growth parameters such as body weight, food intake, organ weight, and tissue weight for each experimental diet group of C57BL/KsJ- $d b / d b$ and C57BL/6J mice are shown in Table 2. The changes in the liver and white adipose tissue (namely visceral fat)weights were strongly affected by n-3HUFA intake and the tendency of those weight increments to be affected by the numbers of double bonds and carbon atoms was observed. Particularly, the weight of the livers in the n-3HUFA groups decreased significantly compared to that in the control group. Comparison of the average weights of the liver and adipose tissue indicates that THA tends to have strong effect for the suppression of weight gain.

\subsection{Lipid profile in liver}

The lipid profiles in the liver among the test groups are compared in Table 3. Levels of TG, total cholesterol, and phospholipid of "mg/whole liver" significantly decreased in all n-3HUFA-administrated groups compared to those in

Table 3 Effect of experimental diet on hepatic lipids in C57BL/6J and C57BL/KsJ-db/db mice (mg/g liver).

\begin{tabular}{|c|c|c|c|c|c|}
\hline & $\begin{array}{c}\text { Normal Control } \\
\text { Group }\end{array}$ & Control roup & EPA-TG Group & DHA-TG Group & THA-TG Group \\
\hline & $(\mathrm{C} 57 \mathrm{BL} / 6 \mathrm{~J})$ & \multicolumn{4}{|c|}{$(\mathrm{C} 57 \mathrm{BL} / \mathrm{KsJ}-d b / d b)$} \\
\hline Triglyceride (mg/g liver) & $28.2 \pm 0.9$ & $180.0 \pm 32.0 *^{\mathrm{a}}$ & $126.0 \pm 14.0^{\mathrm{ab}}$ & $91.7 \pm 11.0^{b}$ & $70.0 \pm 15.7^{b}$ \\
\hline Triglyceride (mg/whole liver) & $25.4 \pm 1.2$ & $357 \pm 83 *^{\mathrm{a}}$ & $218 \pm 33^{a b}$ & $151 \pm 13^{a b}$ & $114 \pm 29^{b}$ \\
\hline Total cholesterol (mg/g liver) & $3.41 \pm 0.10$ & $3.41 \pm 0.16 *$ & $3.20 \pm 0.07$ & $3.10 \pm 0.09$ & $3.17 \pm 0.10$ \\
\hline Total cholesterol (mg/whole liver) & $3.06 \pm 0.06$ & $6.84 \pm 0.38 *^{\mathrm{a}}$ & $5.45 \pm 0.22^{b}$ & $5.21 \pm 0.29^{b}$ & $5.02 \pm 0.21^{\mathrm{b}}$ \\
\hline Phospholipid (mg/g liver) & $33.1 \pm 0.2$ & $27.7 \pm 0.5 *$ & $28.3 \pm 0.9$ & $25.9 \pm 0.5$ & $25.4 \pm 1.1$ \\
\hline Phospholipid (mg/whole liver) & $29.7 \pm 0.5$ & $56.0 \pm 3.7 *^{\mathrm{a}}$ & $48.0 \pm 1.8^{\mathrm{ab}}$ & $43.6 \pm 2.5^{b}$ & $40.5 \pm 3.3^{b}$ \\
\hline
\end{tabular}

Each value represents mean $\pm \mathrm{SE}(\mathrm{n}=5)$.

Different letters indicate significant difference at $p<0.05$ among C57BL/KsJ- $d b / d b$ groups.

$* p<0.05$ (Normal Control vs Control group)

Table 4 Activities of hepatic triglyceride metabolism-related enzymes in C57BL/6J and C57BL/KsJ-db/db mice.

(nmol/min/mg protein)

\begin{tabular}{|c|c|c|c|c|c|}
\hline & $\begin{array}{c}\text { Normal Control } \\
\text { Group }\end{array}$ & Control Group & EPA-TG Group & DHA-TG Group & THA-TG Group \\
\hline & $(\mathrm{C} 57 \mathrm{BL} / 6 \mathrm{~J})$ & \multicolumn{4}{|c|}{$(\mathrm{C} 57 \mathrm{BL} / \mathrm{KsJ}-d b / d b)$} \\
\hline \multicolumn{6}{|l|}{ Cytosol fraction } \\
\hline FAS & $7.42 \pm 0.26$ & $11.3 \pm 1.8 *^{\mathrm{a}}$ & $8.93 \pm 0.69^{\mathrm{ab}}$ & $6.06 \pm 0.55^{b}$ & $4.82 \pm 0.70^{b}$ \\
\hline $\mathrm{ME}$ & $100 \pm 5$ & $137 \pm 19^{a}$ & $114 \pm 10^{\mathrm{ab}}$ & $80.8 \pm 9.8^{b}$ & $76.6 \pm 8.2^{b}$ \\
\hline G6PDH & $7.65 \pm 0.37$ & $4.39 \pm 0.66 *^{\mathrm{a}}$ & $3.88 \pm 0.27^{\mathrm{ab}}$ & $2.91 \pm 0.09^{b}$ & $2.95 \pm 0.06^{\mathrm{ab}}$ \\
\hline \multicolumn{6}{|l|}{ Mitochondrial fraction } \\
\hline $\mathrm{CPT}$ & $8.00 \pm 0.22$ & $10.0 \pm 0.3 *$ & $10.2 \pm 0.2$ & $10.5 \pm 0.4$ & $11.0 \pm 0.3$ \\
\hline Peroxisomal $\beta$-oxidation & $7.55 \pm 0.29$ & $13.1 \pm 0.8 *^{\mathrm{a}}$ & $10.2 \pm 0.2^{b}$ & $11.3 \pm 0.6^{\mathrm{ab}}$ & $11.8 \pm 0.5^{\mathrm{ab}}$ \\
\hline \multicolumn{6}{|l|}{ Microsome fraction } \\
\hline PAP & $16.4 \pm 2.2$ & $4.10 \pm 0.70 *$ & $4.05 \pm 0.51$ & $3.52 \pm 0.29$ & $5.38 \pm 0.25$ \\
\hline
\end{tabular}

Each value represents mean $\pm \mathrm{SE}(\mathrm{n}=5)$.

Different letters indicate significant difference at $p<0.05$ among C57BL/KsJ- $d b / d b$ groups.

$* p<0.05$ (Normal Control vs Control group)

FAS, fatty acid synthase; ME, malic enzyme; G6PDH, glucose 6-phosphate dehydrogenase; CPT, carnitine palmitoyl transferase; PAP, phosphatidate phosphohydrolase 
the control group, and their averages decreased in the order of EPA, DHA, and THA. Consequently, THA showed the strongest suppression effect. In contrast, only the level of TG significantly decreased compared to that in the control group when using the unit "mg/g liver."

\subsection{Hepatic enzyme activity assay}

The activities of hepatic TG metabolism-related enzymes are shown in Table 4. Activity of FAS in the DHA-TG and THA-TG groups, ME treated with the DHA-TG and THA-TG groups, G6PDH treated with the DHA-TG group, and peroxisomal $\beta$-oxidation treated with the EPA-TG group decreased significantly compared to those in the control group.

\subsection{Hepatic mRNA level assay}

The mRNAs related to lipid metabolism are shown in Table 5. mRNA levels of ACC1 in the THA-TG group, FAS in the DHA-TG group, steroyl-CoA desaturase in the THA-TG group, delta 6 desaturase in the DHA-TG group, and MCP in the EPA-TG, DHA-TG, and THA-TG groups decreased significantly compared to those in the control group. No significant difference was detected in the mRNA levels of ACC2 and SREBP-1 between the n-3HUFA-administrated groups and the control group.

\subsection{Lipid profile in serum}

Serum parameters are shown in Table 6. Levels of TG in the EPA-TG group and ALP in the EPA-TG, DHA-TG, and

Table 5 Relative hepatic mRNA levels in C57BL/6J and C57BL/KsJ- $d b / d b$ mice.

\begin{tabular}{|c|c|c|c|c|c|}
\hline & $\begin{array}{c}\text { Normal Control } \\
\text { Group }\end{array}$ & Control Group & EPA-TG Group & DHA-TG Group & THA-TG Group \\
\hline & (C57BL/6J) & \multicolumn{4}{|c|}{$(\mathrm{C} 57 \mathrm{BL} / \mathrm{KsJ}-d b / d b)$} \\
\hline $\mathrm{ACC} 1$ & $17.6 \pm 2.2$ & $100 \pm 7 *^{\mathrm{a}}$ & $82.1 \pm 9.1^{\mathrm{ab}}$ & $74.3 \pm 4.0^{\mathrm{ab}}$ & $72.1 \pm 3.3^{b}$ \\
\hline $\mathrm{ACC} 2$ & $39.0 \pm 4.4$ & $100 \pm 6^{* a b}$ & $112 \pm 10^{\mathrm{a}}$ & $92.8 \pm 7.5^{\mathrm{ab}}$ & $73.4 \pm 8.7^{b}$ \\
\hline FAS & $6.05 \pm 0.64$ & $100 \pm 5 *^{\mathrm{a}}$ & $83.2 \pm 1.3^{\mathrm{ab}}$ & $73.3 \pm 7.0^{b}$ & $79.6 \pm 6.6^{\mathrm{ab}}$ \\
\hline Steroyl-CoA desaturase & $36.6 \pm 5.9$ & $100 \pm 12 *^{\mathrm{a}}$ & $118 \pm 16^{\mathrm{a}}$ & $70.6 \pm 9.0^{\mathrm{ab}}$ & $50.0 \pm 8.2^{b}$ \\
\hline Delta 6 desaturase & $40.8 \pm 3.3$ & $100 \pm 18 *^{\mathrm{a}}$ & $83.3 \pm 10.1^{\mathrm{ab}}$ & $39.1 \pm 3.9^{b}$ & $56.0 \pm 15.9^{\mathrm{ab}}$ \\
\hline SREBP-1 & $60.9 \pm 4.0$ & $100 \pm 12 *$ & $124 \pm 14$ & $126 \pm 12$ & $127 \pm 14$ \\
\hline MCP1 & $13.0 \pm 5.4$ & $100 \pm 11 *^{\mathrm{a}}$ & $35.0 \pm 5.8^{b}$ & $23.3 \pm 4.5^{b}$ & $26.8 \pm 6.2^{b}$ \\
\hline
\end{tabular}

Each value represents mean $\pm \mathrm{SE}(\mathrm{n}=5)$.

Different letters indicate significant difference at $p<0.05$ among C57BL/KsJ- $d b / d b$ groups.

$* p<0.05$ (Normal Control vs Control group)

ACC1, acetyl-CoA carboxylase 1; ACC2, acetyl-CoA carboxylase 2; FAS, fatty acid synthase; SREBP-1, sterol regulatory element binding protein-1; MCP1, monocyte chemotactic protein 1

Table 6 Effect of experimental diet on serum parameters in C57BL/6J and C57BL/KsJ-db/db mice.

\begin{tabular}{|c|c|c|c|c|c|}
\hline & $\begin{array}{c}\text { Normal Control } \\
\text { Group }\end{array}$ & Control Group & EPA-TG Group & DHA-TG Group & THA-TG Group \\
\hline & $(\mathrm{C} 57 \mathrm{BL} / 6 \mathrm{~J})$ & \multicolumn{4}{|c|}{$(\mathrm{C} 57 \mathrm{BL} / \mathrm{KsJ}-d b / d b)$} \\
\hline Triglyceride (mg/dL) & $62.0 \pm 5.3$ & $123.0 \pm 15.0 *^{\mathrm{a}}$ & $80.8 \pm 3.0^{b}$ & $83.5 \pm 6.3^{a b}$ & $87.7 \pm 9.9^{\mathrm{ab}}$ \\
\hline Total cholesterol (mg/dL) & $98.3 \pm 2.1$ & $174 \pm 13 *^{\mathrm{ab}}$ & $137 \pm 5^{\mathrm{a}}$ & $203 \pm 15^{b}$ & $170 \pm 8^{a b}$ \\
\hline Glucose (mg/dL) & $199 \pm 16$ & $578 \pm 72 *$ & $452 \pm 30$ & $492 \pm 29$ & $563 \pm 50$ \\
\hline Insulin (ng/mL) & $0.690 \pm 0.323$ & $7.51 \pm 0.73 *^{\mathrm{a}}$ & $22.4 \pm 5.4^{\mathrm{b}}$ & $18.4 \pm 3.9^{\mathrm{ab}}$ & $10.6 \pm 1.4^{\mathrm{ab}}$ \\
\hline Adiponectin $(\mu \mathrm{g} / \mathrm{mL})$ & $24.5 \pm 1.8$ & $13.3 \pm 0.3 *^{\mathrm{a}}$ & $18.9 \pm 1.0^{b}$ & $20.3 \pm 1.1^{b}$ & $20.0 \pm 0.7^{\mathrm{b}}$ \\
\hline $\mathrm{MCP} 1(\mathrm{pg} / \mathrm{mL})$ & $71.0 \pm 2.1$ & $259 \pm 10 *$ & $243 \pm 16$ & $219 \pm 14$ & $270 \pm 8$ \\
\hline GPT $•$ ALT (IU/L) & $6.00 \pm 0.43$ & $30.0 \pm 2.0 *$ & $23.7 \pm 3.0$ & $25.0 \pm 1.3$ & $25.7 \pm 0.4$ \\
\hline ALP (IU/L) & $61.4 \pm 2.1$ & $121 \pm 4 *^{\mathrm{a}}$ & $91.0 \pm 4.4^{\mathrm{b}}$ & $90.6 \pm 7.0^{\mathrm{b}}$ & $90.8 \pm 5.9^{b}$ \\
\hline
\end{tabular}

Each value represents mean $\pm \mathrm{SE}(\mathrm{n}=5)$.

Different letters indicate significant difference at $p<0.05$ among C57BL/KsJ- $d b / d b$ groups.

$* p<0.05$ (Normal Control vs Control group)

MCP1, monocyte chemotactic protein 1; GPT, glutamate pyruvate transaminase; ALT, alanine aminotransferase

ALP, alkaline phosphatase 
THA-TG groups decreased significantly compared to those in the control group. In contrast, levels of insulin in the EPA-TG group and adiponectin in the EPA-TG, DHA-TG, and THA-TG groups increased significantly compared to those in the control group.

\subsection{Fatty acid composition in organ and tissue}

The fatty acid composition of the organs and tissues is summarized in Fig. 2. 24:6n-3 is characteristically found in the muscles, heart, testis, and spleen of the THA-TG group. Interestingly, the 22:6n-3 content in the liver, muscle, heart, kidney, testis, adrenal gland, and spleen of the THA group was almost the same as those in the DHA-TG group. The relative contents of 20:5n-3 and 22:5n-3 in the muscle, heart, kidney, adrenal gland, and spleen of the EPA-TG group were higher than those of the DHA-TG and THA-TG groups. The relative content of 20:4n-6 in the muscle, heart, kidney, and testis of the control group was characteristically high among C57BL/KsJ- $d b / d b$ mice. Not much content of 18:3n-3 was found in any of the groups. Equally, there was a tendency for a lack of $20: 4 n-6,20: 5 n-3,22: 5 n-$ $3,22: 6 \mathrm{n}-3$, and 24:6n-3 accumulation in the epididymal fat of all the groups. The distribution of fatty acids in the epididymal fat or in the brain was similar among all groups of $\mathrm{C} 57 \mathrm{BL} / \mathrm{KsJ}-d b / d b$ mice and between the normal group (C57BL/6J mice) and the control group (C57BL/KsJ- $d b / d b$ mice).

\section{DISCUSSION}

Metabolic syndrome is gaining attention and visceral fat accumulation and fatty liver are thought to key elements of its mechanism ${ }^{1-3)}$. This accumulation leads to dyschylia of adiponectin and causes insulin resistance, hyperlipidemia, diabetes, and hypertension along with the complications associated with these pathologies that can develop into atherosclerotic diseases ${ }^{33)}$. Particularly, a series of events that include abnormal accumulation of visceral fat, dyschylia of adiponectin, and the development of insulin resistance occur at the center of this pathogenic mechanism, where the first two steps have been most recently studied. We already showed that n-3HUFAs can suppress the accumulation of lipids in HepG2 cells according to the number of carbon atoms and double bonds in the n-3HUFA structure ${ }^{34)}$. This could not only disconnect this series of events in metabolic syndrome, where cardiovascular disease and diabetes occur downstream, but also improve the development of cardiovascular disease and insulin sensitivity as a result. In this study, the hypothesis ${ }^{34)}$ was confirmed using C57BL/KsJ- $d b / d b$ mice. C57BL/KsJ- $d b / d b$ mice carry a G-to-T point mutation at the leptin receptor-coding gene and therefore lack the ability to bind leptin, which leads to an excessive appetite. This has been used as a model animal for the evaluation of obesity, hyperlipidemia, and hyperglycemia, among other conditions. The comparison of growth parameters such as body weight, food intake, organ weight, and tissue weight for each experimental diet group showed that n-3HUFAs significantly affected only weight changes in the liver (Table 2). The weight of the white adipose tissue (namely visceral fat) was also affected by n-3HUFA intake; however, significant differences were not detected and only a tendency affected by the numbers of double bonds and carbon atoms was observed. An accumulation of hepatic lipid would mean that a decrease in liver weight is due to the suppression of TG accumulation (Table 3). Because only TG expressed with "mg/g liver" in n3HUFAs decreased significantly compared to that in the control group, in spite of all the factors expressed with "mg/whole liver" in n-3HUFAs decreased significantly compared to that in the control group. These results suggest that the amount of TG per cell decreased; however, the amounts of total Ch and phospholipids per cell did not differ between the control and n-3HUFA groups. As a result of a significant decrease in TG accumulation in the cell, the total weight of the liver would have decreased significantly, and all the factors expressed as "mg/whole liver" in n-3HUFAs also decreased significantly compared to that in the control group. Consequently, it was thought that the significant decrease in the weight of the liver was caused by the suppression of TG accumulation by n-3HUFAs. The suppression strength tends to be THA $>$ DHA $>$ EPA according to the average values and this order is the same as was confirmed with the HepG2 cell culture test ${ }^{22}$. The accumulation of fat in the liver is also associated with metabolic syndrome. Non-alcoholic fatty liver disease (NAFLD) is now the most common liver disease in Western countries and about $20-30 \%$ of the population is affected by this disease $^{34)}$. NAFLD is strongly associated with features of metabolic syndrome such as insulin resistance ${ }^{35)}$. In accordance with this, the ability of THA to strongly suppress the accumulation of fat in the liver of mice could efficiently prevent the development of metabolic syndrome. The activities of hepatic TG metabolism-related enzymes are shown in Table 4. These results mean that the suppression of fat accumulation in the liver is mainly controlled by the suppression of fatty acid synthesis because FAS and ME activities decreased significantly compared to that in the control. The average values of FAS and ME activity gradually decreased according to an increase in the number of double bonds and carbon atoms in n-3HUFA. Specifically, the suppression ability was THA $>$ DHA $>$ EPA. mRNA data also supports these results and the levels of ACC1 and AAC2 mRNAs, relating to fatty acid synthesis, also decreased according to an increase in the number of double bonds and carbon atoms in n-3HUFA (Table 5). This tendency was also observed in the mRNA for steroyl-CoA desaturase. Monocytes and macrophages play an important 

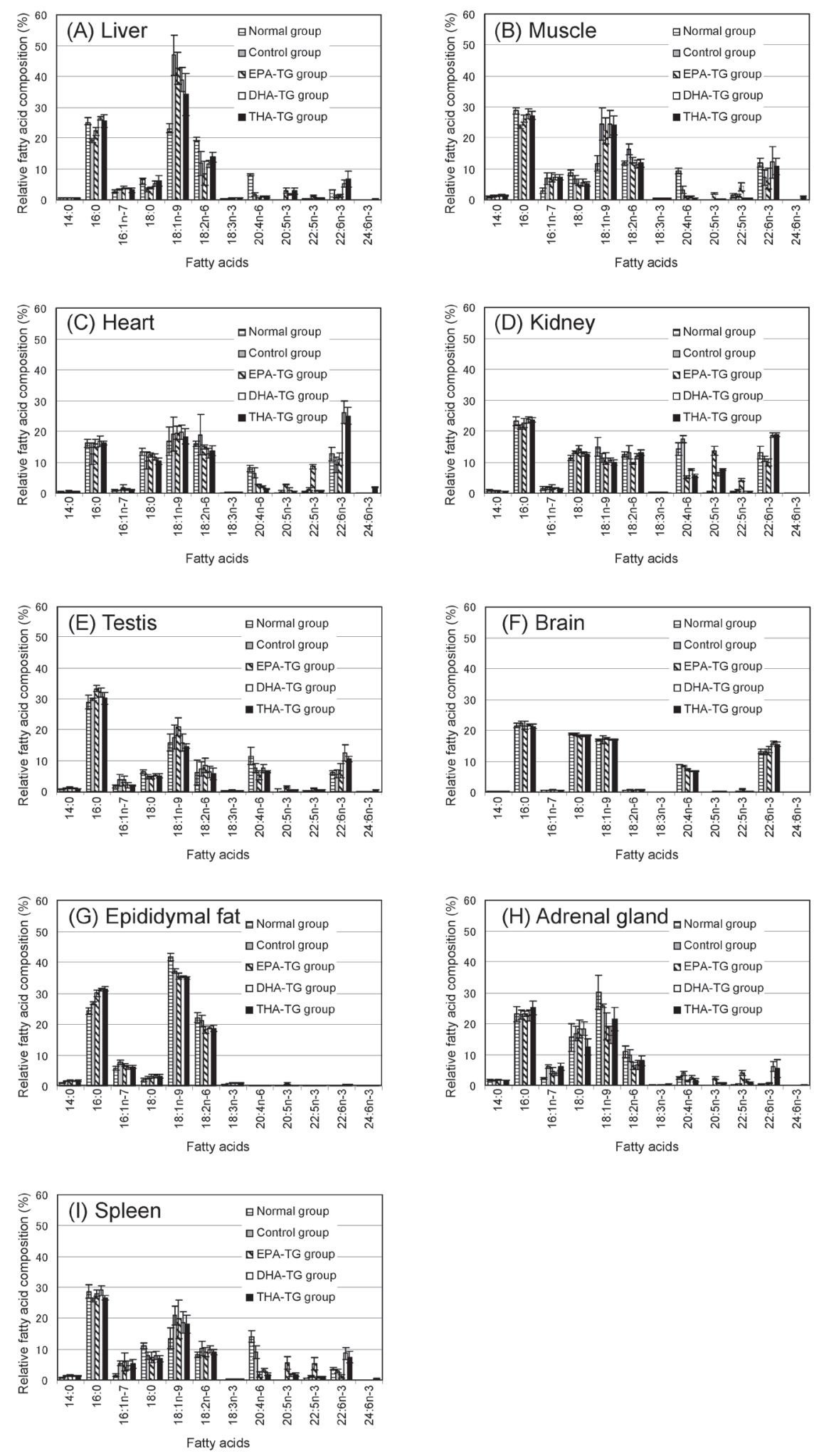

Fig. 2 Comparison of the distribution of the main fatty acids in (A) liver, (B) muscle, (C) heart, (D) kidney, (E) testis, (F) brain, $(\mathrm{G})$ epididymal fat, $(\mathrm{H})$ adrenal gland, and $(\mathrm{I})$ spleen. Values represent mean $\pm \mathrm{SE}(\mathrm{n}=5)$. 14:0; myristic acid, 16:0; palmitic acid, 16:1n-7; palmitoleic acid, 18:0; stearic acid, 18:1n-9; oleic acid, 18:3n-3; $\alpha$-linolenic acid, 20:4n-6; arachidonic acid, 20:5n-3; eicosapentaenoic acid(EPA), 22:5n-3; docosapentanoic acid(DPA), 22:6n-3; docosahexaenoic acid (DHA), 24:6n-3; tetracosahexaenoic acid (THA). 
role in the development of atherosclerosis in vascular endothelial cells; therefore, MCP1 is thought to be one of the key factors for the prevention of cardiovascular disease ${ }^{36)}$. As previously predicted, all n-3HUFAs could suppress the MCP1 mRNA levels significantly compared to that in the control. This result means that n-3HUFAs can suppress metabolic syndrome. It is reported that the gene expression of SREBP1c was suppressed by n-3PUFA ${ }^{37-39)}$. However, our results did not suppress it. Probably, the detection method we employed in this study might be one cause because the method cannot distinguish SREBP1a and $1 \mathrm{c}$. The other reason is the mouse species. The used mouse was C57BL/KsJ- $d b / d b$ mouse. This mouse expresses much SREBP1 compared to normal C57BL6 mouse and this original high SREBP1 level might affect the expression of the mRNA by n-3PUFA administration. However, the suppression would have worked in transcriptive activity level and the suppression of gene expression concerning fatty acid synthesis would occur as the result. In contrast, the suppression ability of TG levels in the serum was in the order EPA $>$ DHA $>$ THA (Table 6). EPA had the strongest ability to suppress the TG level; the same was observed in our previous report. The EPA-TG group had increased insulin levels and this result was the same as in our previous report ${ }^{17}$. Significant increases in adiponectin levels were observed in all n-3 HUFA-TG groups compared to those in the control group. The adiponectin levels in DHA-TG and THA-TG groups were almost the same. These results indicate that the number of double bonds and carbon atoms of n-3HUFA affect the serum parameters. The distribution of fatty acids in the respective group are summarized in Fig. 2. Interestingly, the EPA-TG group characteristically accumulated a high content of $22: 5 n-3$, an intermediate product that is formed from 20:5n-3 to 22:6n-3 in the liver, muscle, heart, kidney, testis, adrenal gland, and spleen of animals. 24:6n-3 is characteristically found in the muscle, heart, testis, and spleen of the THA-TG group; however, the contents were not high even though the mice were administrated 24:6n-3. In contrast, the THA-TG group expressed a relatively high content of 22:6n-3 in the liver, muscle, heart, kidney, testis, adrenal gland, and spleen, and the level was almost the same as that in the DHA-TG group. This fact would mean that most of the administrated 24:6n-3 was beta-oxidized to form 22:6n-3. However, the accumulation of TG in the liver was suppressed in the order of THA(24:6n-3), DHA (22:6n-3), and EPA $(20: 5 n-3)$. There might be a possibility that 24:6n-3 acts as the reserve compound of $22: 6 n-3$ and be converted to $22: 6 \mathrm{n}-3$ when needed because only THA-TG group was detected the accumulation of 24:6n-3 (about $0.3 \%)$ in liver. Therefore, the continuous conversion of 22:6n-3 from 24:6n-3 might succeed in suppressing the accumulation of TG in the liver, lower the hepatic FAS and ME enzymatic activities, and lower hepatic ACC2 mRNA levels, among others. The relative contents of 20:5n-3 and 22:5n-3 in the muscle, heart, kidney, adrenal gland, and spleen of the EPA-TG group were higher than those in the DHA-TG and THA-TG groups. However, the relative content of 22:6n-3 in the EPA-TG group in the organs and tissues was almost the same as that in the control group. These results suggest that the 20:5n-3 administered was converted to 22:5n-3 quickly; however, the formed 22:5n-3 was not converted to 22:6n-3 smoothly. The biosynthesis of 22:6n-3 from 20:5n-3 might be not effective. This idea was supported by previous report ${ }^{40)}$. High relative contents of n-3HUFAs and 20:4n-6 were not detected in epididymal fat. Probably, these functional fatty acids are purposely transferred to organs and tissues where they are needed and not accumulated in the epididymal fat. The fatty acid composition of the brain was almost the same among the 5 groups, even when the mice species were different. It is known that the transportation of fatty acids into the brain is controlled by the blood brain barrier $(\mathrm{BBB})^{41}$. It is likely that the required fatty acid composition of the brain is not different between mice species and would be strictly controlled by the BBB.

\section{CONCLUSION}

THA (24:6n-3) is one of the n-3HUFAs found in marine organisms ${ }^{21)}$. THA is thought to be synthesized positively in starfish. The high accumulation of THA in starfishes could be caused by the decrease in the activation of enzymes related to beta-oxidation to form DHA from THA in the peroxisome of starfish. The accumulation of THA in Baltic herring and the flathead flounder could be related to the food chain because starfish are fish food ${ }^{21}$. Therefore, THA is not a special n-3HUFA and we can obtain it from fish. The order of activities relating to the suppression of hepatic TG and fatty acid synthesis among n-3HUFAs was found to be THA $>$ DHA $>$ EPA in this study. In our previous study, the order was DHA $>$ DPA $>$ EPA. Therefore, a combination of the two results suggests that the order of their activities among n-3HUFAs is THA $>$ DHA $>$ DPA $>$ EPA. This was the same as that observed in the cell experiment and the order clearly translates to the rule that "the number of double bonds and carbon atoms in n-3HUFA structure relates to their health functions". There are many ideas to develop drugs for the treatment or suppression of metabolic syndrome. In this study, the level of cholesterol in the blood was not improved by n-3HUFA; however, other factors such as TG level in the serum and liver, adiponectin levels in the blood, etc., were improved. New drugs for the treatment of metabolic syndrome could be developed using the rule confirmed in this study. The effect of THA on the formation of resolvins and protectins $^{42)}$ was not confirmed in this study and will be our next 
topic of study.

\section{Conflict of interest}

The authors declare no conflicts of interest.

\section{References}

1) Han, T.S.; Lean, M.E. Metabolic syndrome. Medicine 39, 24-31 (2011).

2) Alberti, K.G.M.M.; Zimme, P.; Shaw, J. Metabolic syndrome - a newworld-wide definition. A consensus Statement from the International Diabetes Federation. Diabet. Med. 23, 469-480(2006).

3) Kaur, J. A comprehensive review on metabolic syndrome. Cardiol. Res. Pract. 2014, 943162 (2014).

4) Iso, H. A Japanese health success story: trends in cardiovascular diseases, their risk factors, and the contribution of public health and personalized approaches. EPMA J. 2, 49-57 (2011).

5) Yamagishi, K.; Iso, H.; Date, C.; Fukui, M.; Wakai, K.; Kikuchi, S.; Inaba, Y.; Tanabe, N.; Tamakoshi, A. Fish, $\omega-3$ polyunsaturated fatty acids, and mortality from cardiovascular diseases in a nationwide communitybased Cohort of Japanese men and women. J. Am. Coll. Cardiol. 52, 988-996 (2008).

6) Albracht-Schulte, K.; Kalupahana, N.S.; Ramalingam, L. Wang, S.; Rahman, S.M.; Robert-McComb, J.; Moustaid-Moussa, N. Omega-3 fatty acids in obesity and metabolic syndrome: a mechanistic update. $J$. Nutr. Biochem. 58, 1-16(2018).

7) Gao, H.; Geng, T.; Huang, T.; Zhao, Q. Fish oil supplementation and insulin sensitivity: a systematic review and meta-analysis. Lipids Health Dis. 16, 131 (2017).

8) The American Heart Association's Diet and Lifestyle Recommendations, http:/www.heart.org/HEARTORG/ HealthyLiving/HealthyEating/Nutrition/The-AmericanHeart-Associations-Diet-and-Lifestyle-Recommendations_UCM_305855_Article.jsp\#.WwYZRkjRDcs

9) Reiner, Z.; Catapano, A.L.; De Backer, G.; Graham, I.; Taskinen, M.R.; Wiklund, O.; Agewall, S.; Alegria, E.; Chapman, M.J.; Durrington, P.; Erdine, S.; Halcox, J.; Hobbs, R.; Kjekshus, J.; Filardi, P.P.; Riccardi, G.; Storey, R.F.; Wood, D. ESC/EAS Guidelines for the management of dyslipidaemias: the Task Force for the management of dyslipidaemias of the European Society of Cardiology (ESC) and the European Atherosclerosis Society (EAS). Eur. Heart J. 32, 1769-1818 (2011).

10) Shang, T.; Liu, L.; Zhou, J.; Zhang, M.; Hu, Q.; Fang, M.; Wu, Y.; Yao, P.; Gong, Z. Protective effects of various ratios of DHA/EPA supplementation on high-fat diet- induced liver damage in mice. Lipids Health Dis. 16, 65 (2017).

11) Bradberry, J.C.; Hilleman, D.E. Overview of omega-3 fatty acid therapies. P. T. 38, 681-691 (2013).

12) Todorčević, M.; Hodson, L. The Effect of marine derived n-3 fatty acids on adipose tissue metabolism and function. J. Clin. Med. 5, 3(2016).

13) Allaire, J.; Couture, P.; Leclerc, M.; Charest, A.; Marin, J.; Lépine, M.C.; Talbot, D.; Tchernof, A.; Lamarche, B.; A randomized, crossover, head-to-head comparison of eicosapentaenoic acid and docosahexaenoic acid supplementation to reduce inflammation markers in men and women: the Comparing EPA to DHA(ComparED) Study. Am. J. Clin. Nutr. 104, 280-287 (2016).

14) Yokoyama, M.; Origasa, H.; Matsuzaki, M.; Matsuzawa, Y.; Saito, Y.; Ishikawa, Y.; Oikawa, S.; Sasaki, J.; Hishida, H.; Itakura, H.; Kita, T.; Kitabatake, A.; Nakaya, N.; Sakata, T.; Shimada, K.; Shirato, K. Effects of eicosapentaenoic acid on major coronary events in hypercholesterolaemic patients (JELIS) : a randomised openlabel, blinded endpoint analysis. Lancet 369, 10901098(2007).

15) Ohama, H.; Ikeda, H.; Moriyama, H. Health foods and foods with health claims in Japan. Toxicology 221, 95111 (2006).

16) Ikeda, I.; Yoshida, H.; Tomooka, M.; Yosef, A.; Imaizumi, K.; Tsuji, H.; Seto, A. Effects of long-term feeding of marine oils with different positional distribution of eicosapentaenoic and docosahexaenoic acids on lipid metabolism, eicosanoid production, and platelet aggregation in hypercholesterolemic rats. Lipids 33, 897-904 (1998).

17) Gotoh, N.; Nagao, K.; Onoda, S.; Shirouchi, B.; Furuya, K.; Nagai, T.; Mizobe, H.; Ichioka, K.; Watanabe, H.; Yanagita, T.; Wada, S. Effects of three different highly purified n-3 series highly unsaturated fatty acids on lipid metabolism in C57BL/KsJ-db/db mice. J. Agric. Food Chem. 57, 11047-11054(2009).

18) Qiu, X. Biosynthesis of docosahexaenoic acid (DHA, 22:6-4, 7,10,13,16,19): two distinct pathways. Prostaglandins Leukot. Essent. Fatty Acids 68, 181-186 (2003).

19) Linko, R.R.; Narinkanta, H. Fatty acids of long chain length in Baltic herring lipids. Lipids 47, 42-46 (1970).

20) Tomita, Y.; Ando, Y. Reinvestigation of positional distribution of tetracosahexaenoic acid in triacyl-sn-glycerols of flathead flounder flesh. Fish. Sci. 75, 445-451 (2009).

21) Suo, R.; Li, H.; Yoshinaga, K.; Nagai, T.; Mizobe, H.; Kojima, K.; Nagao, K.; Beppu, F.; Gotoh, N. Generation of tetracosahexaenoic acid in benthic marine organisms. J. Oleo Sci. 64, 721-727 (2015).

22) Nagao, K.; Nakamitsu, K.; Ishida, H.; Yoshinaga, K.; Nagai, T.; Mizobe, H.; Kojima, K.; Yanagita, T.; Beppu, 
F.; Gotoh, N. Comparison of the lipid-lowering effects of four different n-3 highly unsaturated fatty acids in HepG2 cells. J. Oleo Sci. 63, 979-985 (2014).

23) Folch, J.; Lees, M.; Sloane Stanley, G.H. A simple method for the isolation and purification of total lipids from animal tissues. J. Biol. Chem. 226, 497-509 (1957).

24) Fletcher, M.J. A colorimetric method for estimating serum triglycerides. Clin. Chim. Acta 22, 393-397 (1968).

25) Rouser, G.; Siakotos, A.N.; Fleischer, S. Quantitative analysis of phospholipids by thin-layer chromatography and phosphorus analysis of spots. Lipids 1, 85-86 (1966).

26) Lowry, O.H.; Rosebrough, N.J.; Farr, A.L.; Randall, R.J. Protein measurement with the Folin phenol reagent. $J$. Biol. Chem. 193, 265-275 (1951).

27) Kelley, D.S.; Nelson, G.J.; Hunt, J.E. Effect of prior nutritional status on the activity of lipogenic enzymes in primary monolayer cultures of rat hepatocytes. Biochem. J. 235, 87-90 (1986).

28) Kelley, D.S.; Kletzien, R.F. Ethanol modulation of the hormonal and nutritional regulation of glucose 6-phosphate dehydrogenase activity in primary cultures of rat hepatocytes. Biochem. J. 217, 543-549 (1984).

29) Ochoa, S. Malic enzyme. in Merhods in Enzymology (Colowick, S.P.; Kaplan, N.O. eds.) Vol.1, Academic Press, New York, NY, pp. 739-753(1955).

30) Markwell, M.A.; McGroarty, E.J.; Bieber, L.L.; Tolbert, N.E. The subcellular distribution of carnitine acyltransferases in mammalian liver and kidney. A new peroxisomal enzyme. J. Biol. Chem. 248, 3426-3432 (1973).

31) Lazarow, P.B. Assay of peroxisomal-oxidation of fatty acids. in Methods in Enzymology (Lowenstein, J.M. ed.) Vol. 72, Academic Press, New York, NY, pp. 315319 (1981).

32) Walton, P.A.; Possmayer, F. $\mathrm{Mg}^{2+}$-dependent phosphatidate phosphohydrolase of rat lung: development of an assay employing a defined chemical substrate which reflects the phosphohydrolase activity mea- sured using membrane-bound substrate. Anal. Biochem. 151, 479-486 (1985).

33) Matsuzawa, Y.; Funahashi, T.; Kihara, S.; Shimomura, I. Adiponectin and metabolic syndrome. Arterioscler. Thromb. Vasc. Biol. 24, 29-33 (2004).

34) Rusu, E.; Enache, G.; Jinga, M.; Dragut, R.; Nan, R.; Popescu, H.; Parpala, C.; Homentcovschi, C.; Nitescu, M.; Stoian, M.; Costache, A.; Posea, M.; Rusu, F.; Jinga, V.; Mischianu, D.; Radulian, G. Medical nutrition therapy in non-alcoholic fatty liver disease--a review of literature. J. Med. Life 8, 258-262 (2015).

35) Bugianesi, E.; Moscatiello, S.; Ciaravella, M.F.; Marchesini, G. Insulin resistance in nonalcoholic fatty liver disease. Curr. Pharm. Des. 16, 1941-1951 (2010).

36) Jaipersad, A.S.; Lip, G.Y.; Silverman, S.; Shantsila, E. The role of monocytes in angiogenesis and atherosclerosis. J. Am. Coll. Cardiol. 63, 1-11(2014).

37) Davidson, M.H. Mechanisms for the hypotriglyceridemic effect of marine omega-3 fatty acids. Am. J. Cardiol. 98 (suppl), 27i-33i (2006).

38) Adkins, Y.; Kelley, D.S. Mechanisms underlying the cardioprotective effects of omega-3 polyunsaturated fatty acids. J. Nutr. Biochem. 21, 781-792 (2010).

39) Yum, H.W.; Na, H.K.; Surh, Y.J. Anti-inflammatory effects of docosahexaenoic acid: Implications for its cancer chemopreventive potential. Semin. Cancer Biol. 40-41, 141-159(2016).

40) Kaur, G.; Cameron-Smith, D.; Garg, M.; Sinclair, A.J. Docosapentaenoic acid (22:5n-3): a review of its biological effects. Prog. Lipid Res. 50, 28-34(2011).

41) Pan, Y.; Short, J.L.; Choy, K.H.; Zeng, A.X.; Marriott, P.J.; Owada, Y.; Scanlon, M.J.; Porter, C.J.; Nicolazzo, J.A. Fatty acid-binding protein 5 at the blood-brain barrier regulates endogenous brain docosahexaenoic acid levels and cognitive function. J. Neurosci. 36, 11755-11767 (2016).

42) Hong, S.; Lu, Y. Omega-3 fatty acid-derived resolvins and protectins in inflammation resolution and leukocyte functions: targeting novel lipid mediator pathways in mitigation of acute kidney injury. Front. Immunol. 4, 13(2013). 